\title{
Physical activity and the risk of hip fracture in the elderly: a prospective cohort study
}

\author{
Ylva Trolle Lagerros ${ }^{1,2}$ (i) $\cdot$ Essi Hantikainen ${ }^{3} \cdot$ Karl Michaëlsson $^{4} \cdot$ \\ Weimin $\mathrm{Ye}^{5} \cdot$ Hans-Olov Adami ${ }^{5,6,7} \cdot$ Rino Bellocco ${ }^{3,5}$
}

Received: 17 April 2017/Accepted: 6 September 2017/Published online: 22 September 2017

(c) The Author(s) 2017. This article is an open access publication

\begin{abstract}
Physical activity has been inversely associated with the risk of hip fracture, however, few studies have been conducted on the contributions from different domains of physical activity. This study was performed to investigate the association between daily household activities, leisure time physical activity, work-related physical activity and total physical activity during a 24-h period, and the risk of hip fracture. In the Swedish National March Cohort we followed 23,881 men and women aged of 50 and over from 1997 until 2010. Information on domainspecific physical activity was collected at baseline using a questionnaire. We fitted separate multivariable adjusted Cox proportional hazard models to each domain to obtain hazard ratios (HRs) with 95\% confidence intervals (CIs). Each model was mutually adjusted for the other domains of physical activity. During a mean follow-up period of
\end{abstract}

Ylva Trolle Lagerros and Essi Hantikainen share the first authorship.

Electronic supplementary material The online version of this article (doi:10.1007/s10654-017-0312-5) contains supplementary material, which is available to authorized users.

Ylva Trolle Lagerros

ylva.trolle@ki.se

1 Department of Medicine, Clinical Epidemiology Unit T2, Karolinska University Hospital, 17176 Stockholm, Sweden

2 Department of Medicine, Clinic of Endocrinology, Metabolism and Diabetes, Karolinska University Hospital Huddinge, C2:84, 14186 Stockholm, Sweden

3 Department of Statistics and Quantitative Methods, University of Milano-Bicocca, Edificio U7, Via Bicocca degli Arcimboldi 8, 20126 Milan, Italy

4 Department of Surgical Sciences, Section of Orthopedics, Uppsala Clinical Research Center, Akademiska sjukhuset ing. 616 tr, 75185 Uppsala, Sweden
12.2 years we identified 824 incidents of hip fracture. Subjects who spent less than $1 \mathrm{~h}$ per week engaged in daily household activities had an $85 \%$ higher risk of hip fracture than subjects spending $\geq 6 \mathrm{~h}$ per week carrying out daily household activities (HR 1.85; 95\% CI 1.01-3.38). Subjects engaged in leisure time physical activities for $>3.1$ MET-h/day had a $24 \%$ lower risk of hip fracture (HR 0.76; 95\% CI 0.59-0.98) than subjects spending $<1.1$ MET$\mathrm{h} /$ day performing such activities. No association was found between hip fracture and work-related or total physical activity. We conclude that daily household activities and leisure time physical activity may independently decrease the risk of hip fracture in those aged 50 and over.

Keywords Epidemiology $\cdot$ Exercise $\cdot$ Hip fractures $\cdot$ Risk factors

5 Department of Medical Epidemiology and Biostatistics, Karolinska Institutet, PO Box 281, 17177 Stockholm, Sweden

6 Department of Epidemiology, Harvard University T H Chan School of Public Health, 677 Huntington Avenue, Boston, MA 02115, USA

7 Clinical Effectiveness Research Group, Institute of Health and Society, University of Oslo, Sognsvannsveien 21, 0372 Oslo, Norway 


\section{Introduction}

Hip fracture is a major cause of hospitalization, impaired functional status and premature death among older adults. High-risk populations in Europe and North America have exhibited an increase in hip fracture incidence during the past 50 years, making hip fractures a serious public health issue [1]. Concomitantly, enormous changes have taken place in industrialized countries, where labor-intensive work has been replace by automation, and daily life generally requires less physical effort. An increasing proportion of the population has a sedentary lifestyle [2], which may lead to an increase in the incidence of hip fracture [3]. Regular weight-bearing exercise has an osteogenic effect [4-6], and it has been shown that athletes have both a more robust bone structure and improved strength of the femoral neck than non-athletes [7, 8]. In clinical trials, physical activity has been found to reduce falls and fractures through greater muscular strength and improved balance [9-13].

An inverse association has been found between physical activity and the risk of hip fracture in several observational cohort studies focusing on exercise and leisure time physical activity [14-16]. However, the relative contributions of different domains of physical activity, i.e., daily household activities, leisure time physical activity, workrelated physical activity and total physical activity, to the reduction in the risk of hip fracture have not been widely studied. We therefore investigated the possible associations between these different domains of physical activity and the risk of hip fracture in a large prospective study, with a more comprehensive assessment of physical activity than in most previous epidemiological studies.

\section{Subjects and methods}

The Swedish National March Cohort was established in conjunction with a four-day nation-wide fundraising activity organized by the Swedish Cancer Society in September 1997. All those participating in this event were invited to fill in a 36-page questionnaire concerning their physical activity and other lifestyle-related factors, as described previously [17]. Information on hip fractures, death or emigration during the follow-up period, was obtained from other national, continuously updated registers [18]. Accurate linkages between various registersand thus essentially complete follow-up-were possible due to the use of individually unique personal identity numbers in Sweden which are assigned to all Swedish residents [19].
The total number of individuals who were given a questionnaire during the fund-raising event could not be assessed, but 43,880 participants handed in completed questionnaires. Participants who reported an incorrect personal identity number $(\mathrm{n}=11)$, or who had died $(n=11)$ or emigrated $(n=491)$ before the start of the follow-up period were excluded. Furthermore, all subjects below the age of $50(n=19,761)$ were excluded as hip fracture is primarily a problem among the older population. The final study group thus consisted of 23,881 participants (9514 men and 14,367 women). Subjects for whom information was missing on daily household activities $(\mathrm{n}=155,0.7 \%)$, leisure time physical activity $(\mathrm{n}=287$, $1.2 \%)$, work-related physical activity $(n=433,1.8 \%)$, or total physical activity $(\mathrm{n}=2383,10 \%)$ were excluded from the analyses.

All participants gave their informed consent to participate, thus giving their permission to access information on them from national registers. The Ethics Review Committee at Karolinska Institutet approved the study.

\section{Exposure information}

All baseline information was self-reported by means of a questionnaire. Daily household activities were assessed in terms of the average number of hours $(<1,1-2,3-4,5-6$, $>6 \mathrm{~h}$ ) spent per week on activities such as cleaning the house, working in the garden, as well as time spent walking and/or cycling to work.

Leisure time physical activity was assessed in the questionnaire by asking the subjects to report the number of hours per week they were engaged in sports, exercise and outdoor life activities including both summer and winter activities. The activities were divided into three intensity levels: light (e.g. casual walking), moderate (e.g. brisk walking, jogging or swimming), and heavy (e.g. competitive training or vigorous exercise). The reported number of hours was multiplied by the metabolic energy turnover (MET) for each intensity level ( 3 for light, 6 for moderate, 10 for vigorous). One MET corresponds to an energy expenditure of $3.5 \mathrm{ml} \mathrm{O} \mathrm{kg}^{-1} \mathrm{~min}^{-1}$ or $1 \mathrm{kcal}$ per $\mathrm{kg}$ body weight per hour [20]. These values were then converted to provide estimates of MET-h/day.

Work-related physical activity was determined with the question, "How physically demanding has your daily work/occupation been during the past 12 months?". Participants were given the choices "Light, mostly sedentary", "Light, some moving around", "Rather strenuous", and "Very strenuous". If the participant selected either of the strenuous alternatives, they were asked to specify their activity according to the following: "Locomotion, such as walking, running, cycling, climbing or swimming", or 
"Muscle power, such as lifting, bending, pushing, squeezing or twisting", or "Other type of strain".

To assess the total physical activity, participants also completed a question for the quantification of the total energy output associated with all physical activities during a typical $24-h$ period. This assessment had nine fixed categories representing 0.9, 1, 1.5, 2, 3, 4, 5, 6 and 8 METs. Participants were instructed to report the time spent at each intensity level during an average day and night. This provided a measure of their total physical activity, allowing the total MET-h/day to be estimated.

\section{Follow-up}

Follow-up started on October 1st, 1997 and ended on December 31st, 2010, the date of hospitalization for hip fracture, emigration or death, whichever came first. Information on the participants was obtained from the Swedish National Inpatient Register, regarding information on hospital discharge diagnoses, the Swedish Population Register, regarding information on emigration, and the Swedish Cause of Death Register. We defined cases as those subjects who had experienced a hip fracture during the follow-up period, according to the International Coding of Disease (ICD) (ICD-10 codes S720, S721 or S722).

\section{Statistical analyses}

The distribution of continuous and categorical potential confounders was reported by the level of daily household physical activities. Separate Cox proportional hazards regression models, with age as the underlying time scale, were used to estimate hazard ratios (HRs) and 95\% confidence intervals (CIs) for each domain of physical activity. The distributions of leisure time and total physical activity were categorized into quartiles.

The multivariable models were adjusted for the following potential confounders: sex, level of education (7-9, $10-13$ or $>13$ years of education, other); cigarette smoking (never, former, current); body mass index (BMI, $\mathrm{kg} / \mathrm{m}^{2}$ ); diabetes (yes or no, self-reported), and osteoarthritis diagnosed before the beginning of follow-up (yes or no) based on the National Inpatient Register. Information on dietary calcium (mg/day) and vitamin D intake ( $\mu \mathrm{g} /$ day), was derived from a semi-quantitative Food Frequency Questionnaire (FFQ) included in the baseline questionnaire and adjusted for energy intake [21]. We also adjusted the models for the Charlson comorbidity index [22] based on the National Inpatient Register by categorizing it into scores of 0,1 or $>1$ to provide sufficient numbers of subjects in each category. Finally, each model was mutually adjusted for the remaining domains of physical activity to investigate domain-specific associations with the risk of hip fracture.

The proportional hazards assumption was tested using scaled Schoenfeld residuals. Stratified Cox regression models were fitted if the assumption of proportional hazards was violated in the multivariable model. Linear trends for daily household activities and work-related physical activity were investigated by including the values of the categories as continuous variables in the models. For leisure time and total physical activity the median value of each quartile was used as a continuous variable, and we fitted restricted cubic splines with knots at the 5th, 35th, 65 th, and 95th percentiles of the particular exposure variable [23].

We also assessed potential effect modification by age $(<65,65-70,>70$ years $)$ and sex on the multiplicative scale [24] by testing the coefficient of the product term based on the likelihood ratio test comparing nested models. Similarly, we investigated potential interactions between the domains of physical activity.

In the first sensitivity analysis we excluded subjects with hip fractures due to traffic accidents, identified by the code for external cause of injury in the National Inpatient Register. However, this can be questioned as there are indications of comparable increases in the risks of low- and high-impact trauma fractures in association with decreasing bone density in the elderly [25, 26]. As stroke could be associated with hip fracture [27], the analysis was repeated excluding participants who had had a stroke before their hip fracture, based on the National Inpatient Register. We also repeated the analysis excluding subjects with a previous hip fracture $(n=25)$ and with any fracture before the beginning of the follow-up $(n=250)$.

Calcium and vitamin D supplements are common in the prevention of osteoporosis [28]. We therefore further adjusted each model for self-reported vitamin and mineral supplement use (yes, no), and investigated potential effect modification by supplement use. Moreover, hypertension and antihypertensive medication may have an impact on osteoporosis and the risk of fracture [29, 30]. We therefore also adjusted each model for self-reported antihypertensive medication, which was captured in our questionnaire by asking subjects whether they had ever been treated by a doctor for the disease.

The proportion of missing data regarding the confounding variables was $10 \%$ for cigarette smoking, $5 \%$ for BMI, $1.3 \%$ for educational level and less than $1 \%$ for diabetes, dietary calcium and D-vitamin intake. We therefore conducted supplementary analyses after imputing missing data for both exposure and confounders using the multiple imputation chained equation procedure [31].

All statistical analysis was performed with Stata: Release 13 (Statistical Software, College Station, TX: 
StataCorp LP.) Reported probabilities ( $p$ values) were twosided, and values less than 0.05 were considered to indicate statistically significant differences.

\section{Results}

The baseline characteristics of all the subjects, divided according to level of daily household activities, are given in Table 1. The mean age at baseline was 63.1 years (SD 8.3 ), and the cohort consisted of about $60 \%$ women. During the mean follow-up period of 12.2 years there were 824 cases of hip fracture [274 (33.3\%) males and $550(66.7 \%)$ females] among the 23,881 participants, corresponding to $3.45 \%$ of the total sample. Thirty-five of the hip fractures were due to suspected high-energy trauma accidents, and mean age at hip fracture was 80.1 years (SD 7.9 years). At the start of follow-up, $47 \%$ were retired. Subjects who were active more than, or equal to $6 \mathrm{~h}$ per week had a lower BMI, smoked to a lesser degree, had a higher dietary calcium intake, a higher consumption of vitamin and mineral supplements, were more likely to be retired, and spent more time engaged in leisure time physical activities. Diabetes and osteoarthritis were more common among those who were active less than $1 \mathrm{~h}$ per week.

The incidence rates and hazard ratios for hip fracture, according to hours of daily household activities, with the highest activity level as the reference category, are reported in Table 2. We found an inverse association between participating in daily household activities and hip fracture, with the highest HRs in subjects spending less than $1 \mathrm{~h}$ per week on daily household activities (HR 2.13 (CI 95\% 1.32-3.43) compared to subjects in the highest activity level (i.e. $\geq 6 \mathrm{~h}$ a week)). After adjusting for potential

Table 1 Selected baseline characteristics of the participants included in the study, categorized by daily household activity level (for example, gardening, household activities and commuting hours per week)

\begin{tabular}{|c|c|c|c|c|c|c|}
\hline \multirow[t]{2}{*}{ Variable } & & \multirow[b]{2}{*}{$<1$} & \multicolumn{4}{|c|}{ Daily household activities (h/week) } \\
\hline & & & $1-2$ & $3-4$ & $5-6$ & $\geq 6$ \\
\hline Number of participants & Total 23,881 & 356 & 2653 & 6610 & 5395 & 8712 \\
\hline Age (years, mean, SD) & $63.1(8.3)$ & $62.2(9.3)$ & $61.7(8.5)$ & $62.3(8.4)$ & $63.4(8.4)$ & $64.0(8.0)$ \\
\hline Gender $(\%$ men $)$ & 39.8 & 53.9 & 47.3 & 39.3 & 35.9 & 39.8 \\
\hline Height (cm), mean (SD) & $169.5(8.7)$ & $171.5(9.3)$ & $170.8(9.0)$ & $169.6(8.8)$ & $169.0(8.5)$ & $169.3(8.7)$ \\
\hline Weight (kg), mean (SD) & $72.4(12.1)$ & $78.3(13.7)$ & $75.5(13.0)$ & $73.1(12.0)$ & $71.4(11.7)$ & $71.3(11.8)$ \\
\hline Body mass index $\left(\mathrm{kg} / \mathrm{m}^{2}\right)$, mean $(\mathrm{SD})$ & $25.1(3.4)$ & $26.5(3.9)$ & $25.8(3.8)$ & $25.3(3.4)$ & $24.9(3.2)$ & $24.8(3.2)$ \\
\hline Waist circumference $(\mathrm{cm})$, mean $(\mathrm{SD})$ & $86.9(11.8)$ & $93.3(12.4)$ & $89.9(12.4)$ & $87.5(11.8)$ & $86.1(11.6)$ & $86.0(11.4)$ \\
\hline Current smoking $(\%)$ & 5.3 & 10.6 & 7.8 & 6.1 & 4.7 & 5.7 \\
\hline Alcohol (g/month), mean (SD) & $295.2(592.2)$ & $310.2(428.8)$ & 357.7 (1360.9) & $299.2(399.6)$ & $274.7(367.4)$ & $287.0(426.8)$ \\
\hline Education $(\geq 13$ years, $\%)$ & 29.3 & 32.3 & 34.3 & 32.4 & 31.3 & 25.2 \\
\hline Energy intake (kJ/day), mean (SD) & $\begin{array}{l}8784.3 \\
(2661.8)\end{array}$ & $\begin{array}{l}8299.3 \\
(2748.8)\end{array}$ & $\begin{array}{l}8469.9 \\
(2764.6)\end{array}$ & $\begin{array}{l}8571.3 \\
(2622.6)\end{array}$ & $\begin{array}{l}8779.6 \\
(2507.9)\end{array}$ & $\begin{array}{l}9079.5 \\
(2713.4)\end{array}$ \\
\hline Calcium intake (mg/day), mean (SD) & $\begin{array}{l}1200.2 \\
(460.6)\end{array}$ & $\begin{array}{l}1095.6 \\
(487.4)\end{array}$ & $1143.1(488.3)$ & $\begin{array}{l}1169.3 \\
(444.2)\end{array}$ & $\begin{array}{l}1210.5 \\
(448.9)\end{array}$ & $\begin{array}{l}1239.6 \\
(464.5)\end{array}$ \\
\hline Hormonal replacement therapy ${ }^{\mathrm{a}}(\%)$ & 43.4 & 45.3 & 45.3 & 46.9 & 45.3 & 42.8 \\
\hline Vitamin D intake ( $\mu \mathrm{g} /$ day), mean $(\mathrm{SD})$ & $4.3(2.2)$ & $4.1(2.2)$ & $4.1(2.4)$ & $4.2(2.2)$ & $4.4(2.1)$ & $4.5(2.3)$ \\
\hline Diabetes $(\%)$ & 3.5 & 6.8 & 5.0 & 3.8 & 3.2 & 2.9 \\
\hline Charlson comorbidity index, mean (SD) & $0.3(0.8)$ & $0.6(1.3)$ & $0.3(0.9)$ & $0.3(0.8)$ & $0.3(0.8)$ & $0.3(0.8)$ \\
\hline Osteoarthritis (\%) & 2.6 & 5.1 & 3.1 & 2.2 & 2.4 & 2.6 \\
\hline $\begin{array}{l}\text { Leisure time physical activity (METh/day), } \\
\text { mean (SD) }\end{array}$ & $2.3(1.9)$ & $0.8(1.2)$ & $1.3(1.3)$ & $1.8(1.4)$ & $2.3(1.6)$ & $3.1(2.3)$ \\
\hline
\end{tabular}

The Swedish National March Cohort

${ }^{\mathrm{a}}$ Females only 
Table 2 Hip fracture incidence rates and hazard rates (HR), with 95\% confidence intervals (CI) in brackets, for the effect of daily household activities (for example, gardening, household activities and commuting, hours per week) on hip fracture among men and women in the Swedish National March Cohort

\begin{tabular}{|c|c|c|c|c|c|}
\hline & \multirow[b]{2}{*}{$<1$} & \multirow[b]{2}{*}{$1-2$} & \multicolumn{3}{|c|}{ Daily household activities (h/week) } \\
\hline & & & $3-4$ & $5-6$ & $\geq 6$ \\
\hline Number of incident cases of hip fracture & 18 & 95 & 207 & 188 & 302 \\
\hline Person-years & 5732 & 32,200 & 80,744 & 66,027 & 106,983 \\
\hline Incidence rate ${ }^{\mathrm{a}}$ & 581.3 & 389.9 & 312.4 & 306.4 & 294.9 \\
\hline $\operatorname{HR}(95 \% \mathrm{CI})^{\mathrm{b}}$ & $2.13(1.32-3.43)$ & $1.35(1.07-1.70)$ & $1.04(0.87-1.25)$ & $1.01(0.84-1.21)$ & 1.00 (reference) \\
\hline $\operatorname{HR}(95 \% \mathrm{CI})^{\mathrm{c}}$ & $1.85(1.03-3.32)$ & $1.39(1.07-1.82)$ & $1.08(0.89-1.32)$ & $0.90(0.73-1.11)$ & 1.00 (reference) \\
\hline $\operatorname{HR}(95 \% \mathrm{CI})^{\mathrm{d}}$ & $1.85(1.01-3.38)$ & $1.34(1.01-1.78)$ & $1.07(0.87-1.32)$ & $0.86(0.69-1.07)$ & 1.00 (reference) \\
\hline
\end{tabular}

${ }^{\mathrm{a}}$ Incidence rates are adjusted for age and presented per 100,000 person-years

${ }^{\mathrm{b}}$ Adjusted for age at enrollment and gender

${ }^{\mathrm{c}}$ Adjusted for age at enrollment, gender, BMI, educational level, cigarette smoking status, calcium and D-vitamin intake, diabetes, osteoarthritis and Charlson comorbidity index

${ }^{\mathrm{d}}$ Model $\mathrm{c}$ additionally adjusted for leisure time physical activity and work-related physical activity

confounders, the multivariate-adjusted HRs associated with low levels of physical activity were 1.34 (95\% CI $1.01-1.78$ ) for $1-2 \mathrm{~h}$ of daily household activities per week and 1.85 (95\% CI 1.01-3.38) for less than $1 \mathrm{~h}$ per week, compared to subjects engaging in the highest level of daily household activities, with a significant trend $(p$ value $=0.03)$.

After performing sensitivity analysis by excluding fractures due to traffic accidents $(n=35)$, the HR increased slightly to 1.95 (95\% CI 1.07-3.56) for subjects who spent less than $1 \mathrm{~h}$ per week on daily household activities, compared to those spending $\geq 6 \mathrm{~h}$ per week. Excluding subjects with a diagnosis of stroke $(n=2107)$ before the hip fracture increased the HRs for subjects devoting less than $1 \mathrm{~h}$ a week to daily household activities to 2.06 (95\% CI 1.10-3.86), compared to the most active participants. The HR for subjects spending $1-2 \mathrm{~h}$ on daily household activities decreased to 1.28 (95\% CI 0.94-1.74).

An inverse association was also found between leisure time physical activity and hip fracture, with the lowest HR in the third quartile, 1.8-3.1 MET-h/day (HR 0.75; 95\% CI 0.62-0.91), compared to the first $(<1.1 \mathrm{MET}-\mathrm{h} /$ day $)$, and similar values in the fourth quartile ( $>3.1$ MET-h/day) (HR 0.76 ; $95 \%$ CI $0.62-0.93$ ). When adjusting the model for other confounders, the association remained significant for the fourth quartile, with a $24 \%$ lower hazard ratio compared to the first (HR 0.76; 95\% CI 0.59-0.98) and a significant trend $(p$ value $=0.03$ ) (Table 3$)$. The spline regression analysis did not reveal any departure from linearity ( $p$ value $=0.57$ ) (Fig. 1). After excluding fractures caused by traffic accidents, the HR and CI remained almost similar, although non-significant, with a HR of $0.78(95 \%$ CI 0.60-1.01) among those in the highest quartile of physical activity, compared to those in the lowest. In addition, estimates for subjects in the highest quartile did not change after excluding those with a diagnosis of stroke before their hip fracture (HR 0.75 ; 95\% CI 0.57-0.99).

We found no significant association between work-related physical activity and the risk of hip fracture (Supplementary Material, Table 1), nor any association between total physical activity and hip fracture; all the estimated HRs fluctuating around one (Supplementary Material, Table 2). No clear trend was found in the estimated dose-response relationship for total physical activity using spline regression ( $p$ value $=0.26$ )

We did not detect any incidence rate ratio heterogeneity on the multiplicative scale for the statistical interaction between daily household activities, leisure time physical activity, work-related physical activity or total physical activity with age and sex ( $p$ values ranging from 0.07 to $0.84)$. In addition, no significant interactions were found between the different domains of physical activity ( $p$ values ranging from 0.29 to 0.59 ).

After excluding subjects with a previous hip fracture, HRs remained the same (data not shown). Excluding subjects with any type of fracture before the beginning of the follow-up period did not affect the estimates for leisure time physical activity (data not shown). For daily household activities the adjusted HR was similar for subjects spending 1-2 h on daily household activities per week, with a HR of 1.38 (95\% CI 1.03-1.86), and somewhat lower but non-significant for subjects spending less than $1 \mathrm{~h}$ per week on daily household activities, with a HR of 1.66 (95\% CI 0.83-3.30). However, after the exclusion of any fractures, the number of cases in the fully adjusted model for the subgroup being active less than $1 \mathrm{~h}$ per week 
Table 3 Hip fracture incidence rates and hazard rate (HR) with 95\% confidence intervals (CI) for the effect of leisure time physical activity on hip fracture among men and women in the Swedish National March Cohort

\begin{tabular}{lllll}
\hline & \multicolumn{4}{l}{ Quartiles of leisure time physical activity levels (METh/day) } \\
\cline { 2 - 5 } & $<1.1$ & $1.1-1.8$ & $1.8-3.1$ & $>3.1$ \\
\hline Number of incidents of hip fracture & 239 & 226 & 184 & 148 \\
Person-years & 71,052 & 74,122 & 73,683 & 69,654 \\
Incidence rate $^{\mathrm{a}}$ & 330.2 & 280.5 & 244.6 & 238.0 \\
HR (95\% CI) & 1.00 (reference) & $0.85(0.71-1.02)$ & $0.75(0.62-0.91)$ & $0.76(0.62-0.93)$ \\
HR $(95 \% \mathrm{CI})^{\mathrm{c}}$ & 1.00 (reference) & $0.86(0.70-1.06)$ & $0.75(0.61-0.94)$ & $0.70(0.55-0.89)$ \\
HR $(95 \% \mathrm{CI})^{\mathrm{d}}$ & 1.00 (reference) & $0.92(0.74-1.15)$ & $0.83(0.65-1.04)$ & $0.76(0.59-0.98)$ \\
\hline
\end{tabular}

${ }^{\mathrm{a}}$ Incidence rates are adjusted for age and presented per 100,000 person-years

${ }^{\mathrm{b}}$ Adjusted for age at enrollment and gender

${ }^{\mathrm{c}}$ Adjusted for age at enrollment, gender, BMI, educational level, cigarette smoking status, calcium and D-vitamin intake, diabetes, osteoarthritis and Charlson comorbidity index

${ }^{\mathrm{d}}$ Model c additionally adjusted for total daily household activities and work-related physical activity

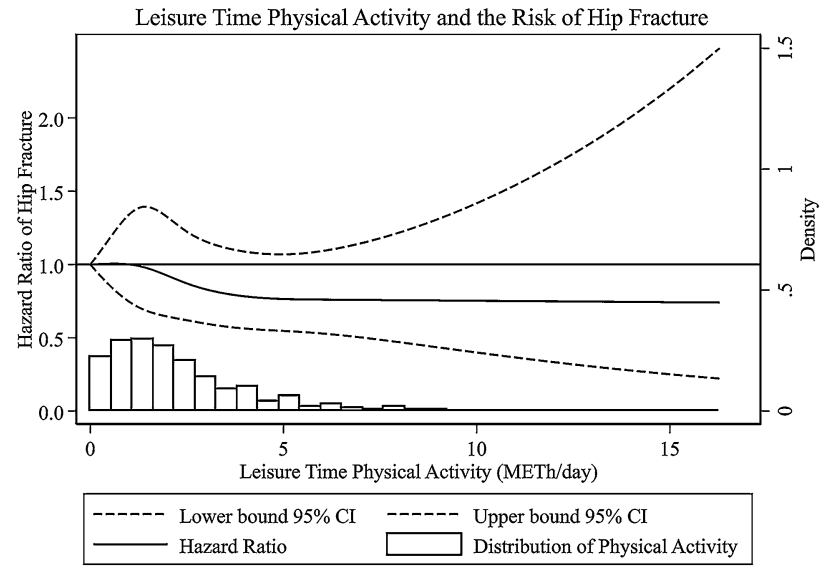

Fig. 1 Multivariable-adjusted restricted cubic spline curve for the relation between leisure time physical activity (continuous, MET$\mathrm{h}$ /day) and the risk of hip fracture. Adjustments were made for age, sex, BMI $\left(\mathrm{kg} / \mathrm{m}^{2}\right)$, educational level $(7-9,10-13$ or $>13$ years of education, other), cigarette smoking (never, former, current), dietary calcium (mg/day) and D-vitamin intake ( $\mu \mathrm{g} /$ day), diabetes (yes, no), osteoarthritis (yes, no), Charlson comorbidity index $(0,1$ or $>1)$, daily household activities (categorical) and work-related physical activity (categorical)

was only 9 , which may have been too small to detect any effect. After further adjustments of the models for the use of vitamin and mineral supplements, HRs remained the same (data not shown). In addition, we found no effect modification between any of the domains of physical activity and supplement use on the multiplicative scale ( $p$ values ranging from 0.47 to 0.86 ). Moreover, adjusting the models for self-reported antihypertensive medication did not affect the pattern of the effect, however, estimates did not reach statistical significance (data not shown).
Furthermore, our results remained stable after carrying out the analysis on the multiple imputed data (data not shown).

\section{Discussion}

In this large prospective cohort study, we found that daily activities such as cleaning, gardening and commuting, as well as leisure time physical activity such as sports, exercise and other outdoor activities, were inversely associated with the risk of hip fracture in men and women. However, no significant associations were found between the risk of hip fracture and work-related physical activity or total physical activity.

Epidemiological studies have convincingly shown that physical activity reduces the risk of hip fracture; most evidence arising from studies focusing on the effect of moderate to vigorous leisure time physical activity and exercise [32]. Our results for leisure time physical activity support these conclusions, showing that more active subjects were at lower risk of hip fracture than the least active subjects. However, few studies have investigated daily activities such as walking, housework, gardening and cycling, which are most prevalent among the older population [33, 34]. A prospective study of 9704 elderly North American women found that spending more than $9 \mathrm{~h}$ per week on heavy household chores reduced the risk of hip fracture by $22 \%$ compared to subjects with an activity duration below $5 \mathrm{~h}$ per week [35]. Two case-control studies conducted among British men and women support these findings $[36,37]$.

In our study, men and women spending less than $3 \mathrm{~h}$ per week on daily household activities were at higher risk of hip fracture than subjects who were active at least $6 \mathrm{~h}$ per 
week. Although the definitions of exposure vary between studies, findings support the hypothesis that participation in daily domestic and commuting activities may help to prevent hip fracture in the elderly. The intensity of such activities can vary from low to vigorous, and we were not able to consider this factor. However, any physical activity, whether conducted during leisure time, or as part of daily household activities, has a positive effect on musculoskeletal and neuromuscular function [38].

Work-related physical activity contributes significantly to total physical activity until the age of retirement (about 65) [39], and may therefore be an important determinant in the risk of fracture. However, we found no significant association between work-related physical activity and the risk of hip fracture. Findings from previous studies are inconsistent [15, 39-42]. In the Women's Health Initiative Observational Study, a large multi-ethnic cohort of 93,676 post-menopausal women, the occupational physical demand of up to three jobs held was considered, but workrelated physical demand was not found to have any effect on the risk of hip fracture [42].

Our study has several limitations. Physical activity and other lifestyle factors were only assessed once, at baseline. We were therefore not able to capture any changes in exposure or potential confounders during follow-up. In the main form of exposure studied, i.e. household tasks, gardening and commuting, we were not able to take into account the intensity of the activity. Furthermore, the frequencies and durations of physical activity in the different domains were self-reported, which could have led to misclassification of the exposure. Our study focused on the population aged 50 and over, and the risk of disease increases with age. Health status is a strong confounder, since healthy subjects may be more physically active than those with an illness [43]. Subjects may change patterns of physical activity after disease onset [44]. If such changes are related to the outcome, this could lead to misclassification and an over- or underestimation of the effect. However, we attempted to consider health status by adjusting our model for potential comorbidity based on the Charlson comorbidity index [22].

We adjusted our analyses for diabetes and osteoarthritis. Although information on osteoarthritis was obtained from national registers, both diabetes and osteoarthritis are known to be under diagnosed. Furthermore, there were few DXA machines available in Sweden in the mid-1990s. There were and is, still no screening program for osteoporosis in Sweden. Thus, some individuals would have had these diseases, although they would not have been diagnosed, which could have led to residual confounding.

The subjects were all invited to take part in the study during a fund-raising event. This may have caused a bias towards healthy volunteers. While population-based cohorts often face the problems of poor response rates and incomplete follow-up, the drawbacks of a non-representative sample must be weighed against the fact that choosing a restricted sample can enhance the feasibility of the study, and increase the prevalence of the exposure and completeness of the follow-up, all of which increase the validity and precision of the study [45]. For example, the level of missing data was unusually low in our study.

The strengths of our study are its prospective design, with a baseline questionnaire covering a number of potential confounding factors, the large sample size, as well as detailed information on different domains of physical activity based on a validated questionnaire. Our outcome is also well defined. Since patients with hip fracture are hospitalized, the follow-up of the incidence of hip fracture was practically completely captured through cross-linkage with the National Inpatient Register.

According to our findings, participation in leisure time physical activities or in daily household activities may, independently of each other, decrease the risk of hip fracture in the older population. This may be an important health message to the elderly population that continuing an active lifestyle is more important than taking part in organized exercise programs in sports or rehabilitation facilities. In addition, a strong determinant for physical inactivity in the elderly population is lack of interest [46]. Therefore, implementing low to moderate activities in a daily routine may be easier and more sustainable, preventing a lapse of physical activity and its consequences later in life.

Acknowledgements We thank Statistics Sweden for scanning the questionnaires. We would also like to thank the Swedish Cancer Society and the volunteers who were involved in data collection. This work was supported by ICA AB; Telefonaktiebolaget LM Ericsson; the Swedish Cancer Society [Grant CAN 2012/591]; a Karolinska Institutet Distinguished Professor Award [2368/10-221 to HOA]; and funds from the regional agreement on medical training and clinical research between Stockholm County Council and Karolinska Institutet [YTL]. The funders played no role in the design of the study, the data collection or the analysis, or in the decision to publish or the preparation of the manuscript.

Authors' contributions Study design: HOA and YTL. Data collection: WY, HOA, RB and YTL. Data analysis: EH and RB. Data interpretation: YLT, EH, RB, WY and KM. Drafting of the manuscript: YTL, EH and RB. Revision of the manuscript: YLT, EH, RB, WY, HOA and KM. All the authors approved the final version of the manuscript. EH and RB take responsibility for the integrity of the data analysis.

\section{Compliance with ethical standards}

Conflict of interest All authors declare that they have no conflict of interest.

Open Access This article is distributed under the terms of the Creative Commons Attribution 4.0 International License (http:// 
creativecommons.org/licenses/by/4.0/), which permits unrestricted use, distribution, and reproduction in any medium, provided you give appropriate credit to the original author(s) and the source, provide a link to the Creative Commons license, and indicate if changes were made.

\section{References}

1. Cummings SR, Melton LJ. Epidemiology and outcomes of osteoporotic fractures. Lancet. 2002;359(9319):1761-7. doi:10. 1016/S0140-6736(02)08657-9.

2. Owen N, Healy GN, Matthews CE, Dunstan DW. Too much sitting: the population health science of sedentary behavior. Exerc Sport Sci Rev. 2010;38(3):105-13. doi:10.1097/JES. 0b013e3181e373a2.

3. Cummings SR, Nevitt MC, Browner WS, et al. Risk factors for hip fracture in white women. Study of Osteoporotic Fractures Research Group. N Engl J Med. 1995;332(12):767-73. doi:10. 1056/NEJM199503233321202.

4. Karlsson MK, Nordqvist A, Karlsson C. Physical activity increases bone mass during growth. Food Nutr Res. 2008; doi:10.3402/fnr.v52i0.1871.

5. Chastin SFM, Mandrichenko O, Skelton DA. The frequency of osteogenic activities and the pattern of intermittence between periods of physical activity and sedentary behaviour affects bone mineral content: the cross-sectional NHANES study. BMC Publ Health. 2014;. doi:10.1186/1471-2458-14-4.

6. Nikander R, Sievanen H, Heinonen A, Daly RM, Uusi-Rasi K, Kannus P. Targeted exercise against osteoporosis: a systematic review and meta-analysis for optimising bone strength throughout life. BMC Med. 2010;8:47. doi:10.1186/1741-7015-8-47.

7. Nikander R, Kannus P, Dastidar P, et al. Targeted exercises against hip fragility. Osteoporos Int. 2009;20(8):1321-8. doi:10. 1007/s00198-008-0785-x.

8. Nikander R, Sievanen H, Heinonen A, Kannus P. Femoral neck structure in adult female athletes subjected to different loading modalities. J Bone Miner Res. 2005;20(3):520-8. doi:10.1359/ JBMR.041119.

9. Robertson MC, Gillespie LD. Fall prevention in communitydwelling older adults. JAMA. 2013;309(13):1406-7. doi:10. 1001/jama.2013.3130.

10. Province MA, Hadley EC, Hornbrook MC, et al. The effects of exercise on falls in elderly patients. A preplanned meta-analysis of the FICSIT trials. Frailty and injuries: cooperative studies of intervention techniques. JAMA. 1995;273(17):1341-7.

11. El-Khoury F, Cassou B, Charles MA, Dargent-Molina P. The effect of fall prevention exercise programmes on fall induced injuries in community dwelling older adults: systematic review and meta-analysis of randomised controlled trials. BMJ. 2013;347:f6234. doi:10.1136/bmj.f6234.

12. Uusi-Rasi K, Patil R, Karinkanta S, et al. Exercise and vitamin D in fall prevention among older women: a randomized clinical trial. JAMA Intern Med. 2015;175(5):703-11. doi:10.1001/ jamainternmed.2015.0225.

13. Karinkanta S, Kannus P, Uusi-Rasi K, Heinonen A, Sievanen H. Combined resistance and balance-jumping exercise reduces older women's injurious falls and fractures: 5-year follow-up study. Age Ageing. 2015;44(5):784-9. doi:10.1093/ageing/afv064.

14. Cawthon PM, Fullman RL, Marshall L, et al. Physical performance and risk of hip fractures in older men. J Bone Miner Res. 2008;23(7):1037-44. doi:10.1359/jbmr.080227.

15. Trimpou P, Landin-Wilhelmsen K, Oden A, Rosengren A, Wilhelmsen L. Male risk factors for hip fracture-a 30-year follow-up study in 7495 men. Osteoporos Int. 2010;21(3):409-16. doi:10. 1007/s00198-009-0961-7.

16. Armstrong ME, Spencer EA, Cairns BJ, et al. Body mass index and physical activity in relation to the incidence of hip fracture in postmenopausal women. J Bone Miner Res. 2011;26(6):1330-8. doi:10.1002/jbmr.315.

17. Lagerros YT, Bellocco R, Adami HO, Nyren O. Measures of physical activity and their correlates: the Swedish National March Cohort. Eur J Epidemiol. 2009;24(4):161-9.

18. Ludvigsson JF, Andersson E, Ekbom A, et al. External review and validation of the Swedish national inpatient register. BMC Publ Health. 2011;11:450. doi:10.1186/1471-2458-11-450.

19. Ludvigsson JF, Otterblad-Olausson P, Pettersson BU, Ekbom A. The Swedish personal identity number: possibilities and pitfalls in healthcare and medical research. Eur $\mathrm{J}$ Epidemiol. 2009;24(11):659-67. doi:10.1007/s10654-009-9350-y.

20. Ainsworth BE, Haskell WL, Leon AS, et al. Compendium of physical activities: classification of energy costs of human physical activities. Med Sci Sports Exerc. 1993;25(1):71-80.

21. Willett WC, Howe GR, Kushi LH. Adjustment for total energy intake in epidemiologic studies. Am J Clin Nutr. 1997;65(4 Suppl):1220S-8S (discussion 9S-31S).

22. Schneeweiss S, Maclure M. Use of comorbidity scores for control of confounding in studies using administrative data bases. Int $\mathbf{J}$ Epidemiol. 2000;29(5):891-8. doi:10.1093/ije/29.5.891.

23. Harrell F. Regression modeling strategies: with applications to linear models, logistic and ordinal regression, and survival analysis. New York: Springer; 2015.

24. Knol MJ, VanderWeele TJ. Recommendations for presenting analyses of effect modification and interaction. Int $\mathrm{J}$ Epidemiol. 2012;41(2):514-20. doi:10.1093/ije/dyr218.

25. Sanders KM, Pasco JA, Ugoni AM, et al. The exclusion of high trauma fractures may underestimate the prevalence of bone fragility fractures in the community: the Geelong Osteoporosis Study. J Bone Miner Res. 1998;13(8):1337-42. doi:10.1359/ jbmr.1998.13.8.1337.

26. Mackey DC, Lui LY, Cawthon PM, et al. High-trauma fractures and low bone mineral density in older women and men. JAMA. 2007;298(20):2381-8. doi:10.1001/jama.298.20.2381.

27. Ramnemark A, Nyberg L, Borssen B, Olsson T, Gustafson Y. Fractures after stroke. Osteoporos Int. 1998;8(1):92-5. doi:10. 1007/s001980050053.

28. Weaver CM, Dawson-Hughes B, Lappe JM, Wallace TC. Calcium plus vitamin D supplementation and the risk of fractures: an updated meta-analysis from the National Osteoporosis Foundation (vol 27, p. 367, 2016). Osteoporosis Int. 2016;27(8):2643-6. doi:10.1007/s00198-016-3699-z.

29. Ilic K, Obradovic N, Vujasinovic Stupar N. The relationship among hypertension, antihypertensive medications, and osteoporosis: a narrative review. Calcif Tissue Int. 2013;92(3):217-27. doi:10.1007/s00223-012-9671-9.

30. Butt DA, Mamdani M, Austin PC, Tu K, Gomes T, Glazier RH. The risk of hip fracture after initiating antihypertensive drugs in the elderly. Arch Intern Med. 2012;172(22):1739-44. doi:10. 1001/2013.jamainternmed.469.

31. Rubin DB, Schenker N. Multiple imputation for interval estimation from simple random samples with ignorable nonresponse. J Am Stat Assoc. 1986;81:366-74.

32. Qu X, Zhang X, Zhai Z, et al. Association between physical activity and risk of fracture. $J$ Bone Miner Res. 2014;29(1):202-11. doi:10.1002/jbmr.2019.

33. DiPietro L. Physical activity in aging: changes in patterns and their relationship to health and function. J Gerontol A Biol Sci Med Sci. 2001;56(2):13-22.

34. Lawlor DA, Taylor M, Bedford C, Ebrahim S. Is housework good for health? Levels of physical activity and factors associated with 
activity in elderly women. Results from the British Women's Heart and Health Study. J Epidemiol Community Health. 2002;56(6):473-8.

35. Gregg EW, Cauley JA, Seeley DG, Ensrud KE, Bauer DC. Physical activity and osteoporotic fracture risk in older women. Study of Osteoporotic Fractures Research Group. Ann Intern Med. 1998;129(2):81-8.

36. Cooper C, Barker DJ, Wickham C. Physical activity, muscle strength, and calcium intake in fracture of the proximal femur in Britain. BMJ. 1988;297(6661):1443-6.

37. Coupland C, Wood D, Cooper C. Physical inactivity is an independent risk factor for hip fracture in the elderly. J Epidemiol Community Health. 1993;47(6):441-3.

38. Gregg EW, Pereira MA, Caspersen CJ. Physical activity, falls, and fractures among older adults: a review of the epidemiologic evidence. J Am Geriatr Soc. 2000;48(8):883-93.

39. Cooper C, Wickham C, Coggon D. Sedentary work in middle life and fracture of the proximal femur. $\mathrm{Br} \mathrm{J}$ Ind Med. 1990;47(1):69-70.

40. Jaglal SB, Kreiger N, Darlington GA. Lifetime occupational physical activity and risk of hip fracture in women. Ann Epidemiol. 1995;5(4):321-4.

41. Farahmand BY, Persson PG, Michaelsson K, et al. Physical activity and hip fracture: a population-based case-control study.
Swedish Hip Fracture Study Group. Int J Epidemiol. 2000;29(2):308-14.

42. Palumbo AJ, Michael YL, Burstyn I, Lee BK, Wallace R. Occupational physical demand and risk of hip fracture in older women. Occup Environ Med. 2015;72(8):567-72. doi:10.1136/ oemed-2014-102670.

43. Moayyeri A. The association between physical activity and osteoporotic fractures: a review of the evidence and implications for future research. Ann Epidemiol. 2008;18(11):827-35. doi:10. 1016/j.annepidem.2008.08.007.

44. Hoidrup S, Sorensen TI, Stroger U, Lauritzen JB, Schroll M, Gronbaek M. Leisure-time physical activity levels and changes in relation to risk of hip fracture in men and women. Am J Epidemiol. 2001;154(1):60-8.

45. Pizzi C, De Stavola B, Merletti F, et al. Sample selection and validity of exposure-disease association estimates in cohort studies. J Epidemiol Community Health. 2011;65(5):407-11. doi:10.1136/jech.2009.107185.

46. Crombie IK, Irvine L, Williams B, et al. Why older people do not participate in leisure time physical activity: a survey of activity levels, beliefs and deterrents. Age Ageing. 2004;33(3):287-92. doi:10.1093/ageing/afh089. 